\title{
A bibliometric analysis of publications in Ambio in the last four decades
}

\author{
Yuh-Shan $\mathrm{Ho}^{1}$ - Andrea Gatto ${ }^{2,3,4}$ (D) \\ Received: 17 December 2020 / Accepted: 4 June 2021 / Published online: 24 July 2021 \\ (C) Crown 2021
}

\begin{abstract}
Ambio is a leading journal in environmental science and policy, sustainable development, and human-environment interactions. The paper at hand aims to run a bibliometric analysis to inspect the main publications features of Ambio in Science Citation Index Expanded SCI-EXPANDED. For this scope, a bibliometric survey has been carried out to investigate the journal's historic characteristics in the Web of Science (WoS) categories of environmental sciences and environmental engineering for Ambio from 1980 to 2019. These are the categories for which the journal has been indexed throughout the indexed time frame. The paper proposes technical and methodological innovations, including improvements in the methods and original characteristics analyzed. Documents published in Ambio were searched out from SCI-EXPANDED. Six publication indicators were applied to evaluate the publication performance of countries, institutes, and authors. Three citation indicators were used to compare publications. As a parameter, the journal impact factor contributor was applied to compare the most frequently cited publications. The journal impact factor contributing publications were also discussed. Results show that Sweden ranked top in six publication indicators and that the top three productive institutes were located in Sweden. A low percentage of productive authors emerged as a journal impact factor contributor. Similarly, a low relationship between the $I F$ contributing publications and the highly cited publications was also found. Less than half of the top 100 highly cited publications in Ambio did not lie within the high impact in most the recent year of 2019. Three members of the advisory board in Ambio were the main productive authors. T.V. Callaghan contributed to most of the publications while papers published by J. Rockstrom as first and corresponding author contributed the most to the journal impact factor. An article authored by Steffen et al. (2007) scored the highest total citations in 2019.
\end{abstract}

Keywords Bibliometrics $\cdot \mathrm{SCI}-\mathrm{EXPANDED} \cdot T C_{\text {year }} \cdot C_{\text {year }} \cdot C P P_{\text {year }} \cdot$ Journal impact factor contributing papers $\cdot \mathrm{Journal}$ impact factor contributing indicators $\cdot$ Journal impact factor contributors $\cdot$ Ambio

JEL codes $\mathrm{C} 0 \cdot \mathrm{I} 2 \cdot \mathrm{Q} 0$

Responsible Editor: Philippe Garrigues

Andrea Gatto

a.gatto@gre.ac.uk

Yuh-Shan Ho

ysho@asia.edu.tw

1 Trend Research Centre, Asia University, No. 500, Lioufeng Road, Wufeng, Taichung 41354, Taiwan

2 Wenzhou-Kean University, Wenzhou 325060, Zhejiang Province, China

3 Natural Resources Institute, University of Greenwich, Central Avenue, Chatham Maritime, Kent ME4 4TB, UK

4 Centre for Studies on Europe, Azerbaijan State University of Economics (UNEC), Baku, Azerbaijan

\section{Introduction}

Ambio is a primary source for environmental scientists and policy analysts, as well as for scholars interested in sustainable development, ecosystem functioning and human-environment interactions. The journal is published by The Royal Swedish Academy of Sciences and was founded in 1971.

Ambio has been indexed in the Science Citation Index Expanded (SCI-EXPANDED) in 1977 and classified in the Web of Science (WoS) categories of environmental engineering and environmental sciences, performing an impact factor of 4.778 in 2019. Currently, Ambio is indexed in four WoS categories: ecology; environmental chemistry; geography, planning and development; medicine. 
Sustainable development, sustainability studies and, more broadly, ecological and resource policy are ascending multidimensional disciplines that deserve devoted research, classification and data (Gatto and Drago 2021; Farrukh et al. 2020; Gatto 2020). Bibliometrics can be a valuable method to map and disentangle existing social science research in applied sciences (Ho and Gatto, 2020) and economics (Drago and Agizza 2019; Drago and Aliberti 2018). Additionally, diverse bibliometric techniques have been employed to wrap up and document complex phenomena and research progress in sustainable development and environmental policy (Gatto et al. 2020; Gatto and Drago 2020; Drago and Aliberti, 2018). Indeed, bibliometrics contemplates the use of diverse techniques, procedures and software to examine a wide range of publication characteristics. A large number of bibliometric analyses has been focusing on capturing the salient information sorting from specific journals' publications (Donthu et al. 2021; Baker et al. 2021). These pieces of evidence addressed and motivated this work's rationale - opting for bibliometric methods that allow portraying past scholarship on the sketched issues, providing a comprehensive quantitative picture of a journal's outputs within the social, economic and environmental sciences.

In the original two categories for which Ambio was first indexed - environmental engineering and environmental sciences - previous bibliometric analyses focusing on selected journals have been presented to study the journals' development and characteristics. This is the case for the Journal of Environmental Engineering and Landscape Management (Xu et al. 2019), the Indoor Air Quality (Pierpaoli and Ruello 2018), the Resources Conservation and Recycling (Ji et al. 2018), the Polish Journal of Environmental Studies (Chuang et al. 2012), Water Research (Wang et al. 2010), Industrial Health (Smith and Leggat 2009), and the Archives of Environmental Health (Smith 2009). Five publication indicators were applied to evaluate the publication performance of countries and institutes in Water Research (Wang et al. 2010). Two citation indicators were presented for highly cited articles and the most impactful articles in the most recent year (Chuang et al. 2012). Citations per publication were used as a variable to compare the impact of document types and countries in the Polish Journal of Environmental Studies (Chuang et al. 2012). Recently, the journal impact factor contributing publications and authors were discussed (Ho 2019). It was pointed out that highly cited papers in a journal might not contribute to the journal impact factor.

In this study, documents published in Ambio from 1980 to 2019 were analyzed. Highly cited papers and authors, as well as the journal impact factor contributing publications and contributors, were examined and discussed. The aim was to explore the dynamics of the most salient publication for the target journal over time. The work also presents methodological innovations and technical improvements to the existing bibliometrics literature-i.e., upgraded procedural inputs and novel analysis proposals.

The remainder of the paper follows this organization: the "Methodology" section inspects the methodology used-i.e., the bibliometric analysis. The "Results and discussion" section presents the outcoming results from the analysis run. In this section, the characteristics of published papers; the characteristics of journal impact factor; the trends of publication numbers and citations per publication; countries, institutions, and authors of the published papers; highly cited papers; and words in title and author keywords are examined. This section also furnishes elements for discussion. Lastly, the "Conclusion" section wraps up the paper's conclusions and presents research limitations and prospects.

\section{Methodology}

The documents used in this study were derived from the SCIEXPANDED of the WoS Core Collection, Clarivate Analytics. The searching keyword phrase "Ambio" was searched as a publication name based on SCI-EXPANDED. The study considered the largest available time frame-i.e., from 1980 to 2019 (updated on December 2, 2020). All document information from SCI-EXPANDED and each year's citation times for every publication sorting from the Web of Science Core Collection was checked and downloaded into Microsoft Excel 2016. Additional coding was manually performed.

The SCI-EXPANDED database was originally designed for researchers to find documents, but it cannot be directly used for bibliometric research (Ho 2018). Therefore, when using the SCI-EXPANDED database, data should be treated before bibliometric processing. The chosen database has been analyzed through Excel. Data were controlled, cleaned and classified. Data were inputted and treated through diverse analysis techniques. To this end, a large number of codes have been exploited to optimize the word filtering and selection, ensuring methodological soundness and overall correctness of this exercise. This includes "proper" and "lower" functions, which have been used to standardize the words - to ensure that similarly written strings were not left behind. This way, when the same words were spelt differently, these could be included in the analysis without misleading overlaps. Another key code was "match," which allowed the possibility to capture one paper published in different countries, taking into account all of them. At the same time, this step facilitated the avoidance of overlappings in the numbers of institutes, countries and additional variables. Further implemented codes included "vlookup" and "concatenate," which were used to guarantee proper network analysis outputs.

The performed research has been undertaken through a brand-new set of feature analysis that has been completed by 
the traditional key publication features explorations. This includes taking into account: (i) selected characteristics percentages and ranks together; (ii) independent studies; (iii) international collaborations; (iv) most performative first authors and corresponding authors; (v) characteristics of the most productive countries; (vi) characteristics of the most productive institutions; (viii) most recurrent words within the publication's title.

The collaboration type, country and institution were determined by the authors' affiliation. In the SCI-EXPANDED database, the corresponding author is designated as the "reprint author". This study uses the term "corresponding author" instead. In a single author publication where the authorship is unspecified, the single author was considered both as first author and corresponding author. Similarly, in a singly institutional publication, the institution is classified as the firstauthor institution and the corresponding-author institution. In multi-corresponding-author articles, only the last corresponding author, institute, and country were considered (see Ho 2019).

The affiliations that originated in England, Scotland, Northern Ireland and Wales were reclassified as UK (United Kingdom). For publications that occurred before 1997, Hong Kong affiliates were included in China. The affiliations in Trinid \& Tabago were included in Trinidad Tobago. The affiliates of Fed Rep Ger (Federal Republic of Germany) and Ger Dem Rep (German Democratic Republic) were also included in Germany. France includes the affiliation of French Guiana. The affiliations in Greenland were included in Denmark. The affiliation of Czechoslovakia was checked and reclassified as the Czech Republic. The affiliation in the USSR (Union of Soviet Socialist Republics) were checked and reclassified as in Russia and Estonia - depending on the institution's nationality. The members of W Ind Assoc St (West Indies Associated States) were reclassified as St Lucia (Saint Lucia) affiliates. Similarly, Geol Survey Czechoslovakia (Geological Survey of Czechoslovakia) was checked and reclassified as Czech Geol Survey (Czech Geological Survey). Acad Sci USSR (the Academy of Sciences of the Soviet Union) was checked and reclassified as Russian Acad Sci (the Russian Academy of Sciences). The same applied to the Acad Med Sci USSR (the USSR Academy of Medical Sciences) - it was checked and reclassified as Russian Acad Med Sci (the Russian Academy of Medical Sciences). Publications by Stockholm Univ and Univ Stockholm were also reclassified as pertaining to Stockholm Univ (Stockholm University in Sweden).

\section{Results and discussion}

\section{Characteristics of document type}

From 1980 to 2019, Ambio published 4154 documents in 10 Web of Science document types.
Table 1 shows the characteristics of these 10 document types, including 3263 articles (79\% of 4154 documents) with a number of authors per publication $(A P P)$ of 3.3. It is worth noting that the documents in the Web of Science Core Collection can be divided into two document types. Among those, 137 documents are classified as conference papers and articles. Therefore, the total percentage is higher than $100 \%$.

Document type of discussions with one document had the highest $A P P$ of 7.0 followed by reviews with 5.8. The average number of authors per publication in the journal was 3.2, and the maximum number of authors was 53 .

The article entitled "Multi-decadal changes in tundra environments and ecosystems: Synthesis of the international polar year-back to the future project (IPY-BTF)" (Callaghan et al. 2011) was published by 53 authors. The co-authors were affiliated to the Royal Swedish Academy of Sciences in Sweden, the University of Sheffield in the UK, and the University of Texas at El Paso in the USA. The $C P P_{2019}$ of the proceedings paper was much higher than other document types, at 65 . Reviews had similar $C P P_{2019}$ than articles. A review entitled "Coupled human and natural systems" (Liu et al. 2007) was co-authored by 15 authors from the USA, Sweden, and China. This paper was the most frequently cited review in Ambio with a $C P P_{2019}$ of 408 .

According to the Web of Science's definition, ${ }^{1}$ the journal impact factor $\left(I F_{\text {year }}\right)$ is defined as in the Journal Citation Reports (JCR) year-i.e., the average number of citations of a journal article published in the past two years. The denominator includes document types of articles or reviews. Some categories of documents that are not normally cited, for example, letters, editorial materials, and other document types are not included in the denominator of the impact factor. Due to the definition of the journal impact factor, only the following document types were considered for further analysis: articles, reviews, and proceedings papers.

\section{Characteristics of the journal impact factor (IF)}

According to the 2019 Journal Citation Reports (JCR), JCR used $178 \mathrm{Web}$ of Science categories in SCI-EXPANDED to index 9381 journals. The journal impact factor $(I F)$ is defined as the sum of all the citations coming from articles published by the journal in the previous two years in the selected JCR year, divided by the total number of academic articles published by the journal (including articles, reviews and proceedings papers). Periodicals of the first two years have observed the following: (https://incites.help.clarivate. $\mathrm{com} /$ Content/Indicators-Handbook/ih-journal-impact-factor. $\mathrm{htm}$ ?Highlight=impact\%20factor).

\footnotetext{
${ }^{1}$ https://support.clarivate.com/ScientificandAcademicResearch/s/article/ Journal-Citation-Reports-Document-Types-Included-in-the-Impact-FactorCalculation?language $=$ en_US.
} 
Table 1 Citations and authors according to document type

\begin{tabular}{llllllll}
\hline Document type & $\mathrm{TP}$ & $\%$ & $\mathrm{TP} *$ & $\mathrm{AU}$ & $\mathrm{APP}$ & $T C_{2019}$ & $C^{*} P_{2019}$ \\
\hline Article & 3263 & 79 & 3256 & 10,853 & 3.3 & 94,489 & 29 \\
Editorial material & 601 & 14 & 577 & 1108 & 1.9 & 2694 & 4.5 \\
Review & 142 & 3.4 & 142 & 820 & 5.8 & 4701 & 33 \\
Proceedings paper & 137 & 3.3 & 137 & 454 & 3.3 & 8848 & 65 \\
Note & 118 & 2.8 & 112 & 158 & 1.4 & 734 & 6.2 \\
Correction & 12 & 0.29 & 12 & 40 & 3.3 & 3 & 0.25 \\
Letter & 9 & 0.22 & 9 & 20 & 2.2 & 59 & 6.6 \\
Addition correction & 7 & 0.17 & 7 & 8 & 1.1 & 1 & 0.14 \\
Biographical-item & 1 & 0.024 & 1 & 3 & 3.0 & 0 & 0 \\
Discussion & 1 & 0.024 & 1 & 7 & 7.0 & 7 & 7.0 \\
\hline
\end{tabular}

$T P$, number of papers; $T P^{*}$, number of papers with author information in SCI-EXPANDED; $A U$, number of authors; $A P P$, number of authors per publication; $T C_{2019}$, the total number of citations from Web of Science Core Collection since publication to the end of 2019; $C P P_{2019}$, number of citations $\left(T C_{2019}\right)$ per publication $(T P)$
The journal impact factor has the following formula:

$I F_{\text {Year }}=\frac{C_{\text {year }-2}+C_{\text {year }-1}}{T P_{\text {Year }-2}+T P_{\text {Year }-1}}$

where $I F_{\text {year }}$ is the journal impact factor in a specific JCR year, $C_{\text {year-2 }}$ : citations from JCR year to items in "year - 2, ," $C_{\text {year-1 }}$ : citations from JCR year to items in "year - 1," $T P_{\text {year-2: }}$ : citable items in "year - 2," $T P_{\text {year-1 }}$ : citable items in "year - $1 . " C N$ : the journal impact factor contributing indicator $\left(C_{\text {year-1 }}+C_{\text {year- } 2}\right)$ that means the citation number of $C_{\text {year-1 }}+C_{\text {year-2. }}$. The denominator is made of three document types such as reviews, articles, and proceedings papers. A research product pertaining to any other document type is excluded from the denominator.

The top 20 journal impact factor $(I F)$ contributing papers were listed in Table 2. 70\%, 20\%, and 10\% of them were published in the 2010s, 2000s, and 1990s, respectively. $75 \%$ and $70 \%$ of the top 20 most $I F$ contributing papers were ranked top 20 in terms of $C N\left(C_{\text {year-2 }}+C_{\text {year- } 1}\right)$, respectively. However, only $25 \%$ and $50 \%$ of them were ranked as top 20 in terms of $T C_{2019}$ and $C_{2019}$, respectively. Only five of the top 20 most contributing papers for the journal impact factor $(I F)$ contributing papers including four articles by Mergler et al. (2007), Scheulhammer et al. (2007), Steffen et al. (2011), and Lindberg et al. (2007) and a review by Madronich et al. (1995), ranked within the top 20 in total citations with $T C_{2019}$ of $699,569,535$, 524 , and 322, respectively. However, 10 of the top 20 highest IF contributing papers - including two in 2007, one in 2011, three in 2014, one in 2016, two in 2017, and one in 2018ranked in the top 20 with a $C_{2019} \geq 43$ as the most impactful papers in the most the recent year-2019. Furthermore, 33\% and $52 \%$ of the top $100 \mathrm{IF}$ contributing papers in terms of $\mathrm{CN}$ were found in the top 100 papers in terms of $T C_{2019}$ and $C_{2019}$, respectively; and only $23 \%$ of the top 100 papers in terms of
$C N$ were found in both the top $100 C_{2019}$ and $T C_{2019}$. It can be concluded that the impact factor of a journal is used to evaluate a journal's relative importance, especially when compared to others in the same field but it is not an appropriate metric when compared to individual research performance. It was also reported in the Web of Science that the journal impact factor $(I F)$ is a paper-level metric. It does not apply to individual papers or subgroups of papers that appeared in the publication. Additionally, it does not apply to authors of papers, research groups, institutions, or universities. ${ }^{2}$ Figure 1 shows the citation histories of the top ten highest journal impact factor contributing papers. Three papers are still keeping an increased trend of citations: Haase et al. (2014), Tengo et al. (2014), and Steffen et al. (2011).

As previously stated, Ambio has been classified in the Web of Science categories of environmental sciences and environmental engineering from its very first indexing. Figure 2 shows its $I F$ and ranking within the subject categories from 1997 to 2019. Within the years, the journal impact factor (IF) fluctuated and slightly increased in the long run, reaching a minimum of 0.929 in 1999 to a maximum of 4.778 in 2019 . The ranking of Ambio in the Web of Science subject categories of environmental sciences and environmental engineering were not improved, especially in the last five years. The journal had a higher ranking in the category of environmental engineering with respect to environmental sciences since 2012. In 2014, notable changes occurred in Ambio's policies, including the enclosure of six major new features (Söderström 2014).

It is clear from Fig. 2 that the journal impact factor increased after that change. The time required to accumulate the citations affects the impact (Garfield 1999). The

\footnotetext{
$\overline{2}$ http://ipscience-help.thomsonreuters.com/inCites2Live/indicatorsGroup/ aboutHandbook/usingCitationIndicatorsWisely/jif.html
} 
Table 2 Top 20 journal impact factor contributing papers in Ambio

\begin{tabular}{|c|c|c|c|c|c|}
\hline Title (reference) & $\begin{array}{l}\text { Rank } \\
(C N)\end{array}$ & $\begin{array}{l}\text { Rank } \\
\left(C_{\text {year-2 }}\right)\end{array}$ & $\begin{array}{l}\text { Rank } \\
\left(C_{\text {year-1 }}\right)\end{array}$ & $\begin{array}{l}\text { Rank } \\
\left(T C_{2019}\right)\end{array}$ & $\begin{array}{l}\text { Rank } \\
\left(C_{2019}\right)\end{array}$ \\
\hline $\begin{array}{l}\text { Sustainable intensification of agriculture for human prosperity and global sustainability (Rockstrom } \\
\text { et al. 2017) }\end{array}$ & $1(145)$ & $1(82)$ & $1(63)$ & $87(159)$ & $5(82)$ \\
\hline Leverage points for sustainability transformation (Abson et al. 2017) & $2(102)$ & $2(58)$ & $3(44)$ & $\begin{array}{l}150 \\
(121)\end{array}$ & $9(58)$ \\
\hline $\begin{array}{l}\text { A synthesis of progress and uncertainties in attributing the sources of mercury in deposition } \\
\text { (Lindberg et al. 2007) }\end{array}$ & $3(76)$ & $3(48)$ & $5(28)$ & $9(524)$ & $26(36)$ \\
\hline $\begin{array}{l}\text { Ecosystem services in urban landscapes: Practical applications and governance implications (Haase } \\
\text { et al. 2014) }\end{array}$ & $4(67)$ & $4(42)$ & $8(25)$ & $24(273)$ & $7(75)$ \\
\hline Methylmercury exposure and health effects in humans: A worldwide concern (Mergler et al. 2007) & $5(59)$ & $6(33)$ & $6(26)$ & $5(699)$ & $8(63)$ \\
\hline $\begin{array}{l}\text { A review of global environmental mercury processes in response to human and natural } \\
\text { perturbations: Changes of emissions, climate, and land use (Obrist et al. 2018) }\end{array}$ & $6(57)$ & $2020(0)$ & $2(57)$ & $299(74)$ & $10(57)$ \\
\hline $\begin{array}{l}\text { Effects of environmental methylmercury on the health of wild birds, mammals, and fish } \\
\text { (Scheulhammer et al. 2007) }\end{array}$ & $7(54)$ & $11(28)$ & $6(26)$ & $7(569)$ & $14(50)$ \\
\hline $\begin{array}{l}\text { Connecting diverse knowledge systems for enhanced ecosystem governance: The multiple } \\
\text { evidence base approach (Tengo et al. 2014) }\end{array}$ & $8(52)$ & $8(30)$ & $12(22)$ & $35(245)$ & $6(80)$ \\
\hline $\begin{array}{l}\text { Contributions of a global network of tree diversity experiments to sustainable forest plantations } \\
\text { (Verheyen et al. 2016) }\end{array}$ & $9(51)$ & $15(26)$ & $8(25)$ & $266(81)$ & $54(22)$ \\
\hline The anthropocene: From global change to planetary stewardship (Steffen et al. 2011) & $10(48)$ & $5(35)$ & $25(13)$ & $8(535)$ & $3(99)$ \\
\hline $\begin{array}{l}\text { When is a forest a forest? Forest concepts and definitions in the era of forest and landscape } \\
\text { restoration (Chazdon et al. 2016) }\end{array}$ & $11(46)$ & $13(27)$ & $14(19)$ & $218(93)$ & $17(43)$ \\
\hline Changes in ultraviolet-radiation reaching the earth's surface (Madronich et al. 1995) & $12(44)$ & $7(32)$ & $30(12)$ & $17(322)$ & $417(5)$ \\
\hline $\begin{array}{l}\text { Ecological and socioeconomic impacts of } 1998 \text { coral mortality in the Indian Ocean: An ENSO } \\
\text { impact and a warning of future change? (Wilkinson et al. 1999) }\end{array}$ & $12(44)$ & $8(30)$ & $22(14)$ & $30(256)$ & $287(7)$ \\
\hline $\begin{array}{l}\text { Reconnecting cities to the biosphere: Stewardship of green infrastructure and urban ecosystem } \\
\text { services (Andersson et al. 2014) }\end{array}$ & $14(42)$ & $10(29)$ & $25(13)$ & $69(176)$ & $13(53)$ \\
\hline Phosphorus management in Europe in a changing world (Schoumans et al. 2015) & $14(42)$ & $36(17)$ & $8(25)$ & $\begin{array}{l}199 \\
(100)\end{array}$ & $31(31)$ \\
\hline $\begin{array}{l}\text { Future agriculture with minimized phosphorus losses to waters: Research needs and direction } \\
\text { (Sharpley et al. 2015) }\end{array}$ & $16(40)$ & $22(21)$ & $14(19)$ & $\begin{array}{l}191 \\
(102)\end{array}$ & $33(30)$ \\
\hline $\begin{array}{l}\text { Changing Arctic snow cover: A review of recent developments and assessment of future needs for } \\
\text { observations, modelling, and impacts (Bokhorst et al. 2016) }\end{array}$ & $17(39)$ & $11(28)$ & $39(11)$ & $425(57)$ & $101(14)$ \\
\hline $\begin{array}{l}\text { Societal transformation in response to global environmental change: A review of emerging } \\
\text { concepts (Feola 2015) }\end{array}$ & $18(36)$ & $25(20)$ & $18(16)$ & $\begin{array}{l}181 \\
(104)\end{array}$ & $24(37)$ \\
\hline $\begin{array}{l}\text { Contribution of ecosystem services to air quality and climate change mitigation policies: The case } \\
\text { of urban forests in Barcelona, Spain (Baró et al. 2014) }\end{array}$ & $18(36)$ & $16(25)$ & $39(11)$ & 159 & $27(34)$ \\
\hline Recovery of mercury-contaminated fisheries (Munthe et al. 2007) & $20(35)$ & $36(17)$ & $16(18)$ & $48(221)$ & $154(11)$ \\
\hline
\end{tabular}

$C N$, journal impact factor contributing indicator $\left(C_{\text {year-1 }}+C_{\text {year- } 2}\right)$

$C_{\text {year-2, }}$, number of citations from JCR year to papers in "year - 2 "

$C_{\text {year- } 1}$, number of citations from JCR year to papers in "year - 1 "

$T C_{2019}$, total number of citations from Web of Science Core Collection since publication year to the end of 2019

$C_{2019}$, total number of citations from Web of Science Core Collection in 2019

size of the scientific community that a journal serves also affects the journal's impact (Garfield 1999). How quickly recent publications are cited is another important factor that can affect $I F$ (Garfield 1999). In general, citations per publication for papers in a journal would have a sharp increase after publication and would reach a peak in a specific year (Fu and Ho 2015; Monge-Nájera and Ho 2016).

Figure 2 shows the citations per publication for each year of paper life. The peak year of citations per publication with
2.5 was found to be in the 3rd full year since its publication. That differed from Revista de Biología Tropical $\left(I F_{2019}=\right.$ 0.446 ) with the peak year in the 7th year (Monge-Nájera and Ho 2016); the Journal of Membrane Science $\left(I F_{2019}=7.183\right)$ in the 4th year (Fu and Ho 2015); and the Journal of Orthopaedic Research $\left(I F_{2019}=2.728\right)$ in the 5 th year $(\mathrm{Ho}$ 2019). A special case not showing a peak was reportedunlike previous findings. However, it shows an increasing trend without a peak after the 9th year for the Polish Journal of Environmental Studies $\left(I F_{2019}=1.383\right)$ 
Fig. 1 Citation histories of the top ten journal impact factor contributing papers

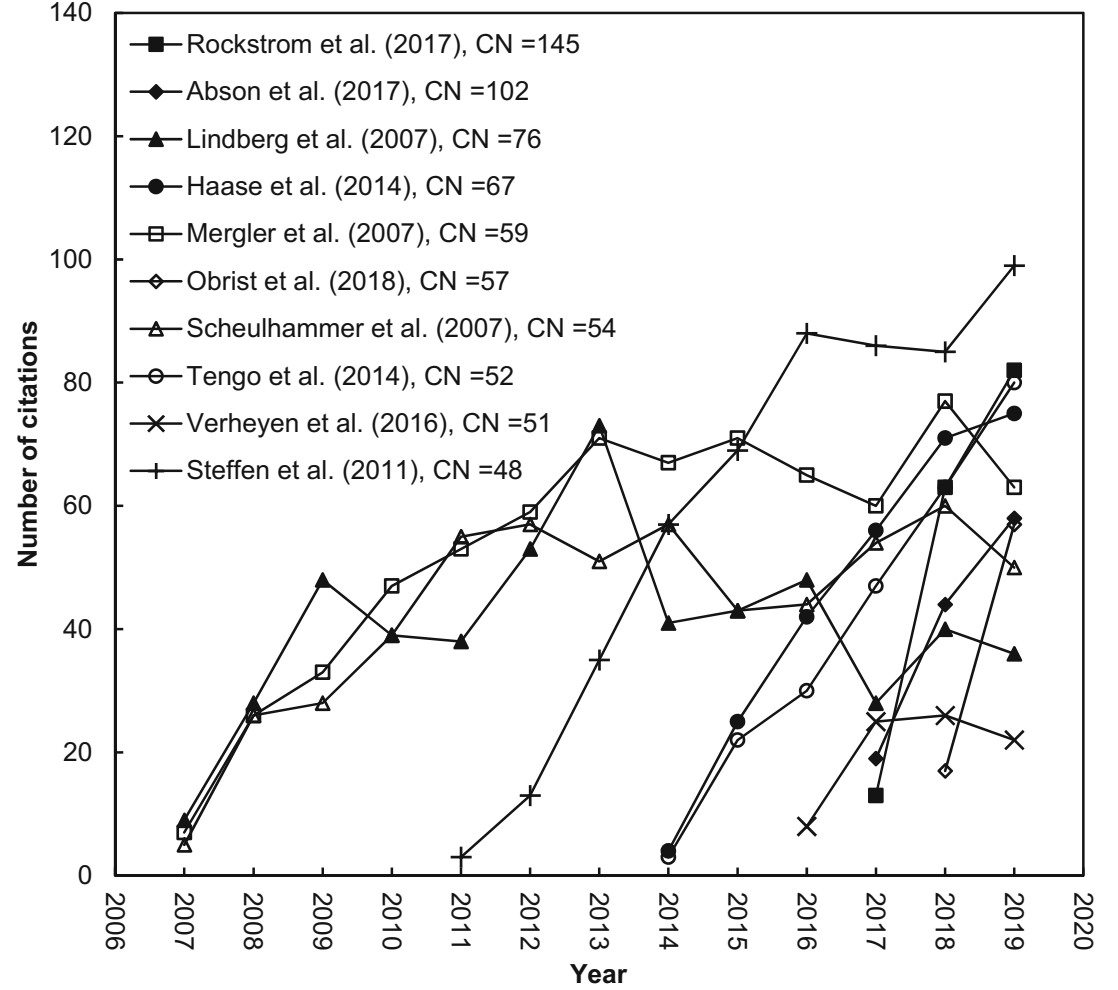

(Chuang et al. 2012). Since the $I F$ only considers citations within two years after publication, the IF of Ambio can be reputed as acceptable. It was pointed out that the $I F$ is not an unbiased criterion for all journals, since peak year citations per publication of each journal can be different from each other (Chuang et al. 2012).
Fig. 2 Rankings of Ambio by journal impact factor in Web of Science categories of environmental sciences and environmental engineering from 1997 to 2019

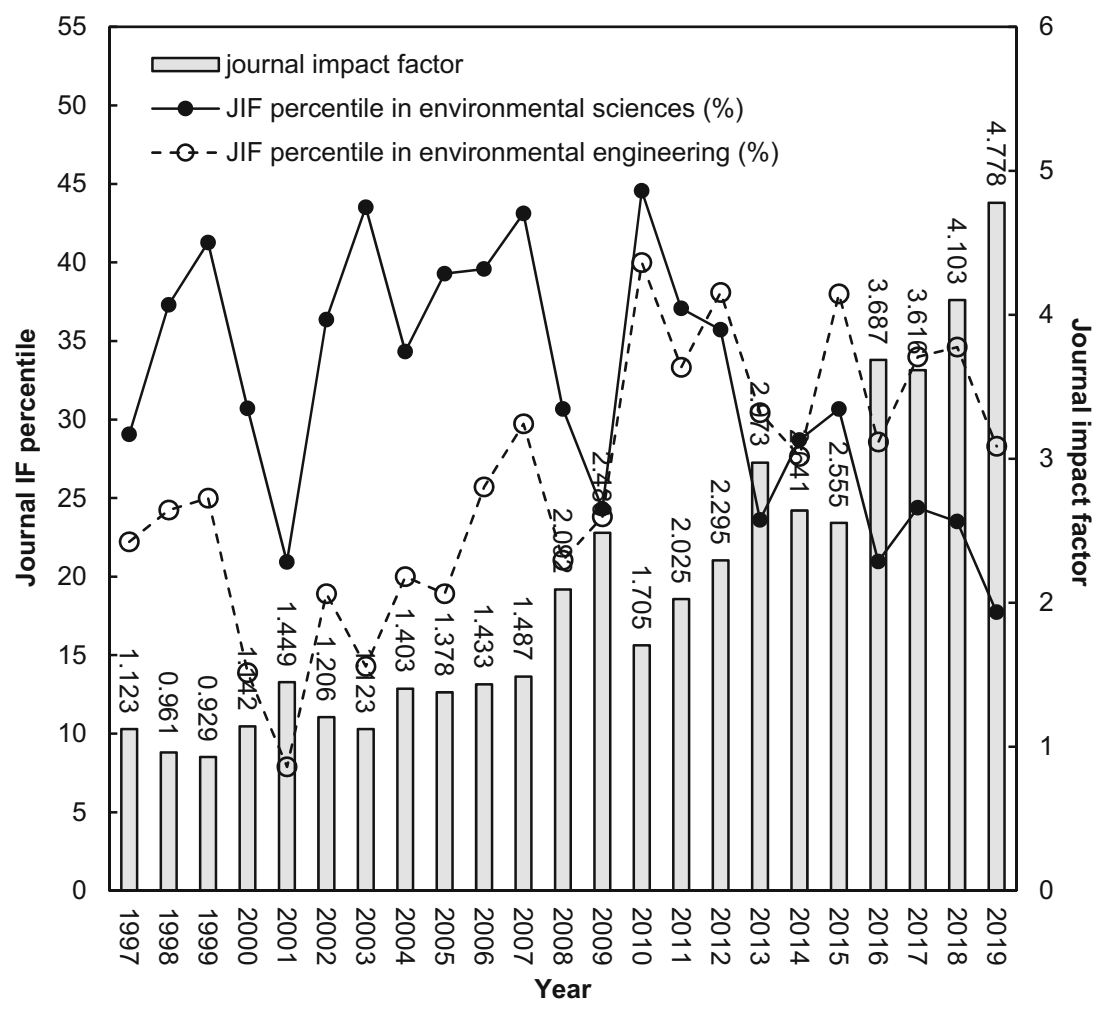




\section{Trends of publication numbers and citations per publication}

The trends of publication numbers show a journal's development, whereas the citations per publication variable provide information about the impact of a journal in the research world. The trends of the number of annual articles $(T P)$ and their citations per publication $\left(C P P_{2019}=T C_{2019} / T P\right)$ have been proposed to discover the development of a journal ( $\mathrm{Fu}$ and $\mathrm{Ho}$ 2015; Monge-Nájera and Ho 2016; Ho 2019). Amidst the 3405 papers including 3263 articles with $C P P_{2019}$ of 29 and 142 reviews $C P P_{2019}$ of 33 published in Ambio were analyzed. The trend of citations per publication is sketched in Fig. 3.

The number of annual papers fluctuated with an increase in the last decade. An average of 85 papers was found from 38 in 1980 to 138 in 1998 (Fig. 4). In 2007, 94 papers had the highest $C P P_{2019}$ of 76 followed by 71 in 2002. Based on Fig. 4, it roughly takes a decade to the $C P P$ s for reaching a plateau. Similarly, results for the Revista de Biología Tropical (MongeNájera and Ho 2016), the Journal of Membrane Science (Fu and Ho 2015), and the Journal of Orthopaedic Research (Ho 2019) also took about one decade to reach a plateau.

\section{Countries, institutions, and authors of the published papers}

Excluding 144 papers without the author's affiliation information on SCI-EXPANDED, the remaining 3261 papers origi- nated from 126 different countries. Among those papers, 2242 (69\% of the 3261 papers) were single country papers from 87 countries, while 1019 (31\%) were internationally collaborative papers from 117 countries. Six publication indicators: number total of papers $(T P)$, country independent papers $(I P)$, internationally collaborative papers $(C P)$, first-author papers $(F P)$, corresponding-author papers $(R P)$, and singleauthor papers $(S P)$ have been applied as criteria to compare the publication's performance of countries and institutes for a research topic (Vega-Arce et al. 2019).

Table 3 shows the top 10 most contributing countries with the six publication indicators presented. Six European countries including four countries in Scandinavia, two in America, one in Oceania, and one in Asia were ranked on the top 10 of total papers. The most productive African country was Tanzania with 56 papers (ranked 19th). Sweden dominated in Ambio, ranking as the first in all six publication indicators with a TP of 1080 papers (33\% of 3261 papers), an IP of 639 papers (29\% of 2242 country independent papers), a $C P$ of 441 papers (43\% of 1019 internationally collaborative papers), an $F P$ of 879 papers (27\% of 3261 first-author papers), an $R P$ of 872 papers (27\% of 3227 corresponding-author papers), and an $S P$ of 186 papers (22\% of 838 single-author papers).

Of the total 3261 papers with affiliation information in SCI-EXPANDED, 1447 papers (44\% of 3261 papers) came from independent institutions with a $C P P_{2019}$ of 25 and 1814 papers $(56 \%)$ from inter-institutional collaborations with a
Fig. 3 Trend of citations per publication

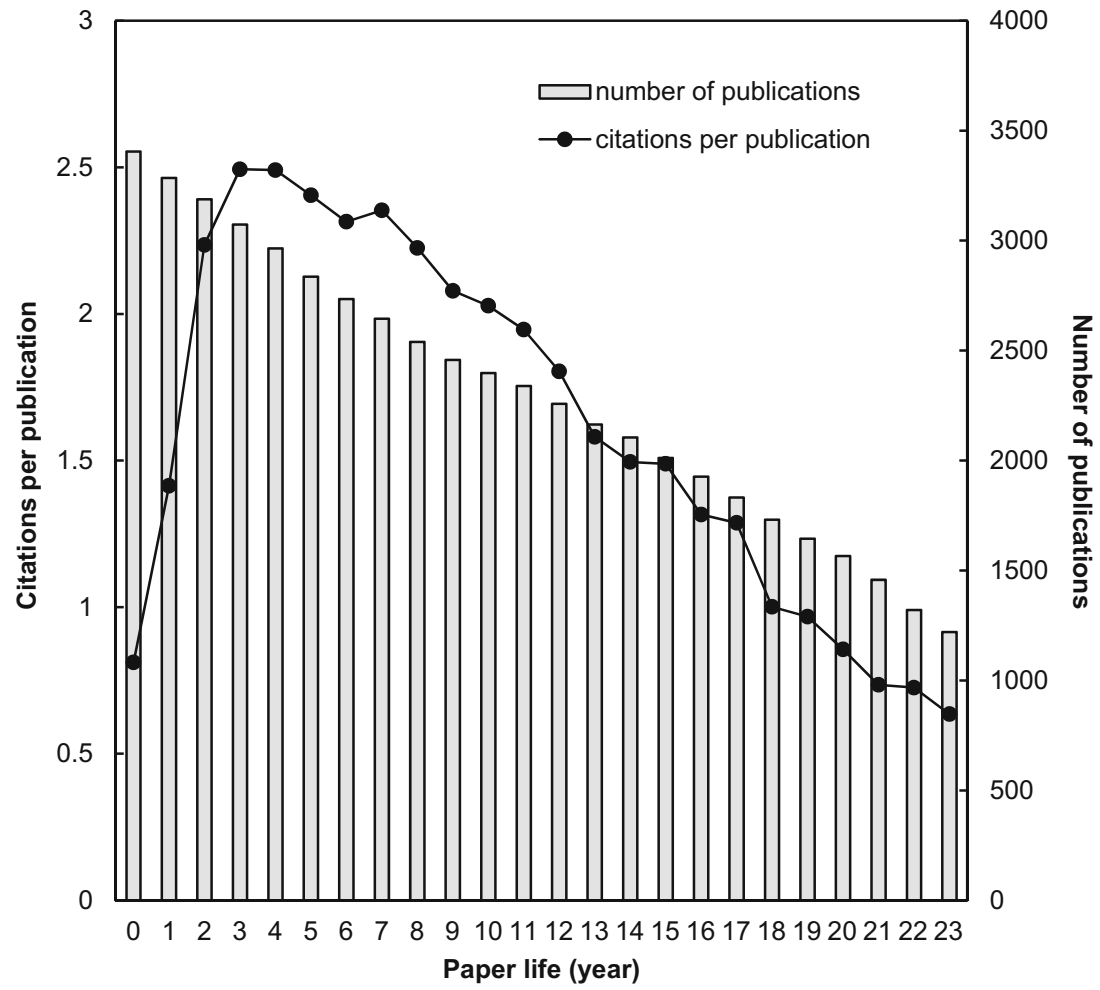


Fig. 4 Number of papers and citations per publication versus year for Ambio

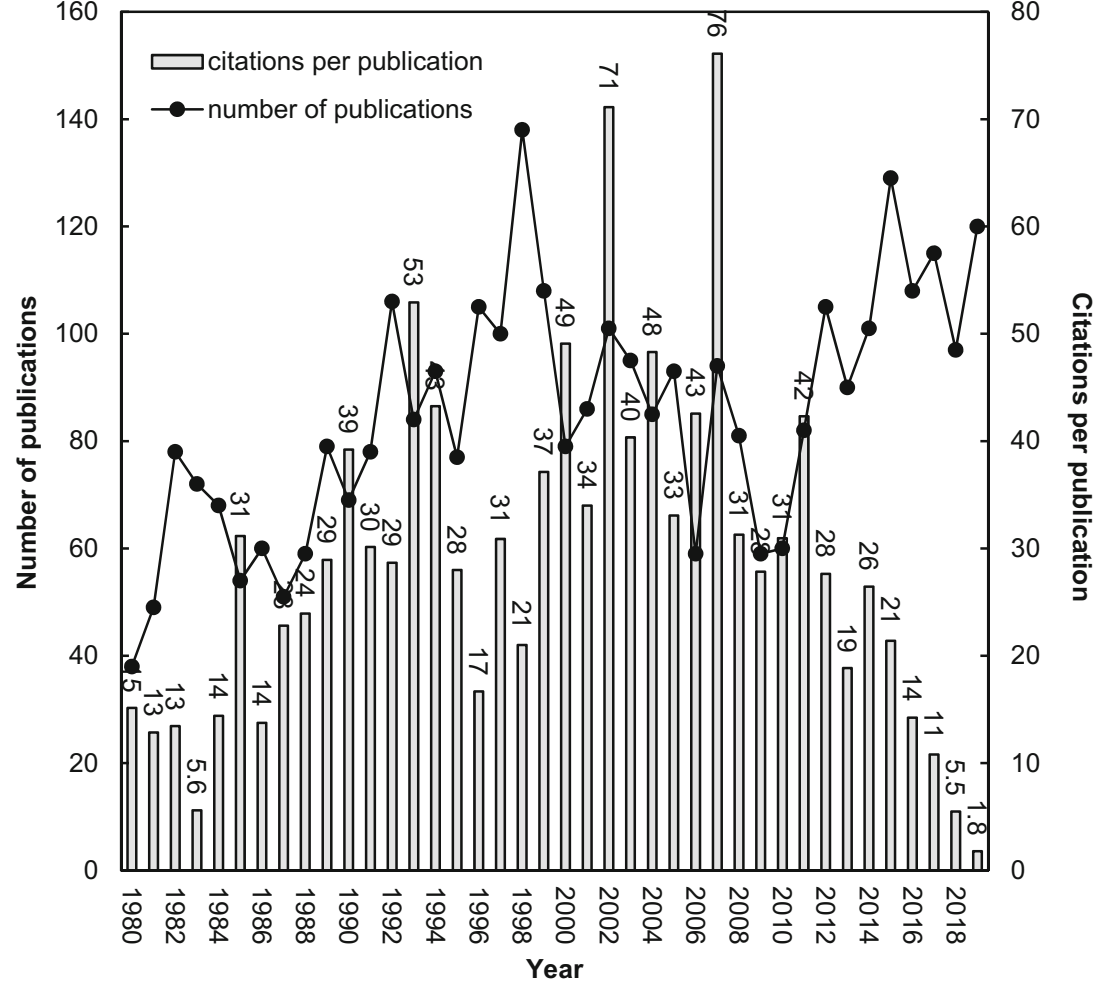

$C P P_{2019}$ of 34 . The percentage of the inter-institutional collaboration rate of the Ambio (56\%) was found higher than that of J. Membr. Sci. (38\%) (Fu and Ho 2015), and Pol. J. Environ. Stud. (31\%) (Chuang et al. 2012), but lower than that of J. Orthop. Res. (63\%) (Ho 2019).

The characteristics of the top 10 productive institutions with the six publication indicators were listed in Table 4 (Vega-Arce et al. 2019). Seven of the top ten institutes were located in Sweden. The University of Helsinki in Finland ranked 4th, Aarhus University in Denmark ranked 8th and the University of Copenhagen in Denmark ranked 10th. Stockholm University in Sweden took the leading position in five of the six publication indicators with a TP of 308 papers $(9.4 \%$ of 3261 papers), an IP of 68 papers (4.7\% of 1447 institutional independent papers), a $C P$ of 240 papers (13\% of 1814 inter-institutionally collaborative papers), an FP of 159 papers (4.9\% of 3261 firstauthor papers), and an RP of 157 papers (4.9\% of 3227 corresponding-author papers) while the Swedish University of Agricultural Sciences in Sweden took the leading position with an $S P$ of 27 papers $(3.2 \%$ of 838 single-author papers).
Table 3 Characteristics of the top 10 productive countries

\begin{tabular}{|c|c|c|c|c|c|c|c|}
\hline Country & $T P$ & $\begin{array}{l}T P \\
R(\%)\end{array}$ & $\begin{array}{l}I P \\
R(\%)\end{array}$ & $\begin{array}{l}C P \\
R(\%)\end{array}$ & $\begin{array}{l}F P \\
R(\%)\end{array}$ & $\begin{array}{l}R P \\
R(\%)\end{array}$ & $\begin{array}{l}S P \\
R(\%)\end{array}$ \\
\hline Sweden & 1080 & $1(33)$ & $1(29)$ & $1(43)$ & $1(27)$ & $1(27)$ & $1(22)$ \\
\hline USA & 760 & $2(23)$ & $2(18)$ & $2(36)$ & $2(16)$ & $2(16)$ & $2(18)$ \\
\hline UK & 372 & $3(11)$ & $3(6.3)$ & $3(23)$ & $3(7.1)$ & $3(7.1)$ & $3(9.4)$ \\
\hline Canada & 232 & $4(7.1)$ & $4(4.2)$ & $4(13)$ & $4(4.7)$ & $4(4.8)$ & $4(3.7)$ \\
\hline Finland & 216 & $5(6.6)$ & $5(4.2)$ & $6(12)$ & $5(4.2)$ & $5(4.2)$ & $6(2.7)$ \\
\hline Norway & 198 & $6(6.1)$ & $7(3.1)$ & $5(13)$ & $6(3.1)$ & $6(3.1)$ & $14(1.4)$ \\
\hline Germany & 175 & $7(5.4)$ & $10(2.4)$ & $7(12)$ & $10(2.6)$ & $10(2.7)$ & $9(2.3)$ \\
\hline Denmark & 170 & $8(5.2)$ & $11(2.4)$ & $8(11)$ & $9(2.9)$ & $9(2.9)$ & $12(1.7)$ \\
\hline Australia & 162 & $9(5.0)$ & $8(2.8)$ & $9(10)$ & $7(3.0)$ & $7(3.0)$ & $4(3.7)$ \\
\hline China & 139 & $10(4.3)$ & $6(3.3)$ & $11(6.5)$ & $7(3.0)$ & $7(3.0)$ & $8(2.4)$ \\
\hline
\end{tabular}

$T P$, total number of papers; $I P$, country independent papers; $C P$, internationally collaborative papers; $F P$, firstauthor papers; $R P$, corresponding-author papers; $S P$, single-author papers 
Table 4 Characteristics of the top 10 productive institutes

\begin{tabular}{|c|c|c|c|c|c|c|c|}
\hline Institute & $T P$ & $T P R(\%)$ & $I P R(\%)$ & $C P R(\%)$ & $F P R(\%)$ & $R P R(\%)$ & $S P R(\%)$ \\
\hline Stockholm University, Sweden & 308 & $1(9.4)$ & $1(4.7)$ & $1(13)$ & $1(4.9)$ & $1(4.9)$ & $2(3.0)$ \\
\hline Swedish University of Agricultural Sciences, Sweden & 225 & $2(6.9)$ & $2(4.4)$ & $2(8.9)$ & $2(4.1)$ & $2(4.1)$ & $1(3.2)$ \\
\hline Lund University, Sweden & 88 & $3(2.7)$ & $9(0.90)$ & $3(4.1)$ & $6(1.1)$ & $6(1.1)$ & $31(0.36)$ \\
\hline University of Helsinki, Finland & 83 & $4(2.5)$ & $3(1.2)$ & $5(3.6)$ & $6(1.1)$ & $6(1.1)$ & $8(0.72)$ \\
\hline Umea University, Sweden & 80 & $5(2.5)$ & $10(0.76)$ & $4(3.8)$ & $4(1.3)$ & $4(1.3)$ & $12(0.60)$ \\
\hline University of Gothenburg, Sweden & 79 & $6(2.4)$ & $7(1.0)$ & $6(3.5)$ & $3(1.5)$ & $3(1.5)$ & $3(1.4)$ \\
\hline Royal Swedish Academy of Sciences, Sweden & 78 & $7(2.4)$ & $8(1.0)$ & $6(3.5)$ & $5(1.2)$ & $5(1.2)$ & $5(1.2)$ \\
\hline Aarhus University, Denmark & 63 & $8(1.9)$ & $21(0.41)$ & $8(3.1)$ & $10(0.86)$ & $9(0.87)$ & N/A \\
\hline Uppsala University, Sweden & 62 & $9(1.9)$ & $14(0.62)$ & $10(2.9)$ & $12(0.83)$ & $9(0.87)$ & $8(0.72)$ \\
\hline University of Copenhagen, Denmark & 57 & $10(1.7)$ & $68(0.21)$ & $9(3.0)$ & $20(0.49)$ & $20(0.5)$ & N/A \\
\hline
\end{tabular}

$T P$, total number of papers; $I P$, institute independent papers; $C P$, inter-institutionally collaborative papers; $F P$, first-author papers; $R P$, correspondingauthor papers; $S P$, single-author papers; $C P P_{2019}$, citations per publication $\left(C P P_{2019}=T C_{2019} / T P\right) ; N / A$, not available

With the exception of seven anonymous papers , 3398 papers were published by 8431 authors including 2798 authors who published first-author papers, 2733 authors who published corresponding-author papers, and 834 authors who published single-author papers. The first author and the corresponding author are the most significant author positions (Gaeta 1999; Mattsson et al. 2011). Three bibliometric indicators such as total papers $(T P)$, first-author papers $(F P)$, corresponding-author papers $(R P)$, and single-author papers $(S P)$ were applied for the analysis of authors' characteristics for papers in a research field.

Table 5 lists the top 17 productive authors with 13 papers in Ambio. T.V. Callaghan $\left(C P P_{2019}=43 ; C N=247\right)$, who is a member of the advisory board in Ambio, affiliated to the Royal Swedish Academy of Sciences in Sweden, was the largest contributor with 40 papers including seven reviews and 33 articles. Callaghan also ranked top in first-author papers with 20 items and corresponding-author papers with 19 publications. F. Barnaby $\left(C P P_{2019}=2.0 ; C N=11\right)$ ranked the top in single-author papers with 12. M. Johansson $\left(C P P_{2019}=46\right.$; $C N=163$ ) with 27 papers ranked second in total papers and T.R. Christensen $\left(C P P_{2019}=34 ; C N=109\right)$ with 22 papers ranked third, both of Johansson and Christensen were from Lund University in Sweden. C. Folke $\left(C P P_{2019}=227 ; C N=\right.$ 278 ) with 20 papers from the Stockholm University in Sweden and T.D. Prowse $\left(C P P_{2019}=50 ; C N=72\right)$ with 18 papers from the University of Victoria in Canada were also sitting in the advisory board of Ambio.

E. Andersson $\left(C P P_{2019}=424 ; C N=100\right)$ from Stockholm University in Sweden was the most productive associate editor in Ambio, and published seven articles. Comparing the top 24 most productive authors, an advisory board member - C. Folke - with one review and 19 articles, had the highest $C P P_{2019}$ of 227, followed by T. Elmqvist (16 papers; $\left.C P P_{2019}=181\right)$ and $\mathrm{F}$. Wulff $\left(13 ; C P P_{2019}=111\right)$ from Stockholm University, respectively. T. Elmqvist from
Stockholm University was the journal impact factor best contributor with the highest $C N\left(C_{\text {year-1 }}+C_{\text {year-2 }}\right)$ of 290 , followed by $\mathrm{C}$. Folke from the same university with a $C N$ of 278, and T.V. Callaghan from Royal Swedish Academy of Sciences with a $C N$ of 247 . The most productive authors, C. Folke and T. Elmqvist also published the top largest number of papers falling within the 100 journal impact factor contributing papers with five contributions, respectively. A.D. Fox, C. Folke, J.N. Galloway, T.V. Callaghan, and W. Steffen published two first-author papers and corresponding-author papers in the top 100 journal impact factor contributing papers.

The article entitled "Sustainable intensification of agriculture for human prosperity and global sustainability" (Rockstrom et al. 2017) was the best contributing article in terms of journal impact factor in Ambio with a $C N$ of 145 followed by the article entitled "Leverage points for sustainability transformation" (Abson et al. 2017) with a $C N$ of 102. Furthermore, only $26 \%$ and $25 \%$ of the top 100 productive authors were ranked in the top 100 in terms of $C N$ of their first author and corresponding author, respectively. J. Rockstrom from Stockholm University published five papers in Ambio including two first-author papers and two correspondingauthor papers. Rockstrom had the highest $C N$ of 150 for his first-author papers and corresponding-author papers, respectively. D.J. Abson from Leuphana University of Luneburg in Germany published two papers in Ambio including one firstauthored paper and one corresponding-author paper. Abson had the second-highest $C N$ of 102 for his first-author papers and corresponding-author papers, respectively.

\section{Highly cited papers}

The total number of citations was obtained from the Web of Science Core Collection as the bibliometric indicator, $T C_{2019}$. The main research fescues in a research topic might be 
Table 5 Characteristics of the top 24 productive authors with $T P \geq$ 12

\begin{tabular}{|c|c|c|c|c|c|c|c|}
\hline Author & Rank $(T P)$ & Rank $(F P)$ & Rank $(R P)$ & $\operatorname{Rank}(S P)$ & $T C_{2019}$ & $C P P_{2019}$ & $\mathrm{CN}$ \\
\hline T.V. Callaghan & $1(40)$ & $1(20)$ & $1(19)$ & $72(1)$ & 1712 & 43 & 247 \\
\hline M. Johansson & $2(27)$ & $52(3)$ & $49(3)$ & N/A & 1234 & 46 & 163 \\
\hline T.R. Christensen & $3(22)$ & $52(3)$ & $49(3)$ & $\mathrm{N} / \mathrm{A}$ & 737 & 34 & 109 \\
\hline C. Folke & $4(20)$ & $13(5)$ & $25(4)$ & N/A & 4539 & 227 & 278 \\
\hline P. Angelstam & $5(18)$ & $6(8)$ & $3(9)$ & N/A & 939 & 52 & 91 \\
\hline T.D. Prowse & $5(18)$ & $4(9)$ & $3(9)$ & N/A & 903 & 50 & 72 \\
\hline A. Bergman & 7 (17) & $28(4)$ & $25(4)$ & N/A & 864 & 51 & 98 \\
\hline M. Olsson & $7(17)$ & $13(5)$ & $12(5)$ & N/A & 882 & 52 & 84 \\
\hline O. Linden & $7(17)$ & $28(4)$ & $25(4)$ & $23(2)$ & 685 & 40 & 87 \\
\hline L.O. Bjorn & $10(16)$ & $109(2)$ & $107(2)$ & N/A & 1106 & 69 & 27 \\
\hline H.E.M. Meier & $10(16)$ & $13(5)$ & $12(5)$ & N/A & 621 & 39 & 110 \\
\hline T. Elmqvist & $10(16)$ & $367(1)$ & $364(1)$ & N/A & 2899 & 181 & 290 \\
\hline J.D. Reist & $13(14)$ & $52(3)$ & $49(3)$ & N/A & 829 & 59 & 52 \\
\hline P. Okeefe & $13(14)$ & $10(6)$ & $8(6)$ & $23(2)$ & 43 & 3.1 & 13 \\
\hline S. Lofgren & $15(13)$ & $13(5)$ & $12(5)$ & N/A & 320 & 25 & 57 \\
\hline F. Barnaby & $15(13)$ & $2(13)$ & $2(12)$ & $1(12)$ & 26 & 2.0 & 11 \\
\hline F. Wulff & $15(13)$ & $10(6)$ & $8(6)$ & N/A & 1438 & 111 & 109 \\
\hline A. Bignert & $18(12)$ & N/A & N/A & N/A & 485 & 40 & 57 \\
\hline M.C. Ohman & $18(12)$ & $52(3)$ & $49(3)$ & N/A & 419 & 35 & 25 \\
\hline R. Axelsson & $18(12)$ & $109(2)$ & $107(2)$ & N/A & 337 & 28 & 58 \\
\hline H. Laudon & $18(12)$ & $109(2)$ & 107 (2) & N/A & 249 & 21 & 97 \\
\hline W.F. Vincent & $18(12)$ & $367(1)$ & $364(1)$ & $\mathrm{N} / \mathrm{A}$ & 656 & 55 & 49 \\
\hline M. Elbakidze & $18(12)$ & $52(3)$ & $49(3)$ & N/A & 337 & 28 & 58 \\
\hline S. Jonasson & $18(12)$ & N/A & N/A & N/A & 478 & 40 & 37 \\
\hline
\end{tabular}

$T P$, total number of papers; $F P$, first-author papers; $R P$, corresponding-author papers; $T C_{2019}$, the total number of citations from Web of Science Core Collection since publication year to the end of 2019; $C P P_{2019}$, citations per publication $\left(C P P_{2019}=T C_{2019} / T P\right) ; C N, C_{\text {year-1 }}+C_{\text {year- } 2} ; C_{\text {year-1 }}$, number of citations from JCR year to papers in "year - 1"; $C_{\text {year-2, }}$, number of citations from JCR year to papers in "year - 2"; $N / A$, not available reflected by highly cited articles. Highly cited papers in JAMA-Journal of the American Medical Association (Garfield 1997), Water Research (Wang et al. 2010), and Polish Journal of Environmental Studies (Chuang et al. 2012) were presented. Articles with a $T C_{\text {year }}$ of 100 or more, were generally called highly cited articles (Ho and Gatto, 2020).

In Ambio, 202 (5.9\%) of 3405 papers were highly cited papers including one classic article with a $T C_{2019}$ of 1126 . The 202 highly cited papers were published by 836 highly cited authors from 412 institutions in 45 countries. The USA had 86 highly cited papers (43\% of 200 highly cited papers with affiliation information in SCI-EXPANDED) followed by Sweden (73 articles; 37\%), Canada (28; 14\%), the UK (24; $12 \%)$, and Germany $(20 ; 10 \%)$. Stockholm University in Sweden published 32 of 202 highly cited papers (16\% of the 202 Royal Swedish Academy of Sciences) followed by the Swedish University of Agricultural Sciences, Royal Swedish Academy of Sciences, and Lund University in Sweden with 10 papers. C. Folke published the most cited papers in the
Ambio with 12 papers including the most four first-author and corresponding-author papers, respectively.

The top 20 most frequently cited papers were listed in Table 6 . Five of the top 20 highly cited papers were published in 2002 and 2007, respectively. Six and 17 of the top 20 most frequently cited papers were ranked top 20 in terms of $C N$ $\left(C_{\text {year-2 }}+C_{\text {year- }-1}\right)$, respectively while five and 10 of them were ranked top 20 in terms of $C N$ and $C_{2019}$, respectively. The five of the top 20 most frequently cited papers including four articles by Lindberg et al. (2007), Mergler et al. (2007), Scheulhammer et al. (2007), and Steffen et al. (2011) and a review by Madronich et al. (1995) ranked in the top 20 most $I F$ contributing papers with a $C N$ of $76,59,54,48$, and 44 , respectively. Ten of the top 20 most frequently cited papers in Ambio were published by Steffen et al. (2007), Folke et al. (2002), Steffen et al. (2011), Cassman et al. (2002), Mergler et al. (2007), Liu et al. (2007), Scheulhammer et al. (2007), Costanza et al. (2008), Galloway and Cowling (2002), and Gadgil et al. (1993), and were also ranked the top 20 in $C_{2019}$ as the most impactful papers in 2019. The only classic 
publication with a $T C_{2019}$ of 1000 or more was an article entitled "The Anthropocene: Are humans now overwhelming the great forces of nature" (Steffen et al. 2007) published by Steffen et al., written by scholars whose affiliations were from Australia, Germany, and the USA. This most frequently cited article in Ambio was also the most impactful in most the recent year of 2019 with a $C_{2019}$ of 144 .

Citation histories of the top ten most frequently cited papers in Ambio are shown in Fig. 5. The classic article by Steffen et al. (2007) had a sharply increased trend after its publication for a decade and then decreased in 2019. Similarly, highly cited articles by Folke et al. (2002) and Steffen et al. (2011) also had an increasing trend. The highly cited article by Wania and Mackay (1993) had an increasing trend after publication for two full years and keep in a plateau. Highly cited papers would not always have a high impact or visibility after publication. Furthermore, only 45 of the top 100 papers in terms of $C_{2019}$ were found in the top 100 in terms of $T C_{2019}$ in Ambio.

\section{Words in title and author keywords}

Several scholars proposed the distribution of words in article titles, abstracts, author keywords, and KeyWords Plus in different periods as information to evaluate main research focuses and find their development trends in research topics (Ho and Gatto, 2020). Table 7 showed the top 20 most used words in the paper title. The distribution of the words in four decades was also presented in the table. "Baltic" was the most recurrent word, used in 218 paper titles (6.4\% of 3405 papers), followed by management, sea, change, environmental, and climate. "Change" and "climate" were the most popular terms in the last decade. The author's keywords can be found only in the 2010s in Ambio. The top ten used author's keywords were "climate change," that can be found in 118 papers (12\% of 989 papers in the 2010s), followed by "ecosystem services" (53 papers; 5.4\%), "Baltic sea" (47; 5.4\%), "eutrophication" (41; 4.1\%), "sustainability" (32; 3.2\%), "biodiversity" (31;

Table 6 Top 20 highly cited papers in Ambio

\begin{tabular}{|c|c|c|c|c|}
\hline $\begin{array}{l}\text { Rank } \\
\left(T C_{2019}\right)\end{array}$ & $\begin{array}{l}\text { Rank } \\
\left(C_{2019}\right)\end{array}$ & $\begin{array}{l}\text { Rank } \\
(C N)\end{array}$ & Titles & References \\
\hline $1(1126)$ & $1(144)$ & $46(24)$ & The Anthropocene: Are humans now overwhelming the great forces of nature & Steffen et al. (2007) \\
\hline $2(991)$ & $2(121)$ & $94(16)$ & $\begin{array}{l}\text { Resilience and sustainable development: Building adaptive capacity in a world of } \\
\text { transformations }\end{array}$ & Folke et al. (2002) \\
\hline $3(777)$ & $3(99)$ & $197(11)$ & Agroecosystems, nitrogen-use efficiency, and nitrogen management & Cassman et al. (2002) \\
\hline $4(755)$ & $16(46)$ & $37(27)$ & Reactive nitrogen and the world: 200 years of change & $\begin{array}{l}\text { Galloway and Cowling } \\
\text { (2002) }\end{array}$ \\
\hline $5(699)$ & $8(63)$ & $5(59)$ & Methylmercury exposure and health effects in humans: A worldwide concern & Mergler et al. (2007) \\
\hline $6(649)$ & $49(24)$ & $24(32)$ & $\begin{array}{l}\text { Global fractionation and cold condensation of low volatility organochlorine } \\
\text { compounds in polar regions }\end{array}$ & $\begin{array}{l}\text { Wania and Mackay } \\
\text { (1993) }\end{array}$ \\
\hline $7(569)$ & $14(50)$ & $7(54)$ & Effects of environmental methylmercury on the health of wild birds, mammals, and fish & $\begin{array}{l}\text { Scheulhammer et al. } \\
\text { (2007) }\end{array}$ \\
\hline $8(535)$ & $3(99)$ & $10(48)$ & The anthropocene: From global change to planetary stewardship & Steffen et al. (2011) \\
\hline $9(524)$ & $26(36)$ & $3(76)$ & $\begin{array}{l}\text { A synthesis of progress and uncertainties in attributing the sources of mercury in } \\
\text { deposition }\end{array}$ & Lindberg et al. (2007) \\
\hline $10(510)$ & $20(38)$ & $434(7)$ & Indigenous knowledge for biodiversity conservation & Gadgil et al. (1993) \\
\hline $11(501)$ & $287(7)$ & $43(25)$ & The ammonium hypothesis: An additional explanation to the forest dieback in Europe & Nihlgard (1985) \\
\hline $12(449)$ & $42(26)$ & $72(18)$ & Nitrogen in aquatic ecosystems & Rabalais (2002) \\
\hline $13(408)$ & $12(55)$ & $136(13)$ & Coupled human and natural systems & Liu et al. (2007) \\
\hline $14(385)$ & $83(17)$ & $156(12)$ & Reserves, resilience and dynamic landscapes & Bengtsson et al. (2003) \\
\hline $15(366)$ & $63(21)$ & $46(24)$ & The globalization of nitrogen deposition: Consequences for terrestrial ecosystems & Matson et al. (2002) \\
\hline $16(363)$ & $287(7)$ & $197(11)$ & Eutrophication and the Baltic Sea: Causes and consequences & Larsson et al. (1985) \\
\hline $17(322)$ & $417(5)$ & $12(44)$ & Changes in ultraviolet radiation reaching the earth's surface & Madronich et al. (1995) \\
\hline $18(312)$ & $15(49)$ & $156(12)$ & The value of coastal wetlands for hurricane protection & Costanza et al. (2008) \\
\hline 19 (307) & $175(10)$ & $43(25)$ & How warm was the medieval warm period & $\begin{array}{l}\text { Crowley and Lowery } \\
(2000)\end{array}$ \\
\hline $20(305)$ & $175(10)$ & $156(12)$ & Nutrient limitation of primary production in the Baltic Sea area & Graneli et al. (1990) \\
\hline
\end{tabular}

$T C_{2019}$, total number of citations from Web of Science Core Collection since publication year to the end of 2019

$C_{2019}$, total number of citations from Web of Science Core Collection in 2019

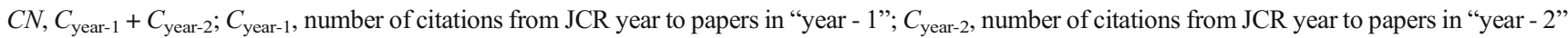


Fig. 5 Citation histories of the top ten most frequently cited papers

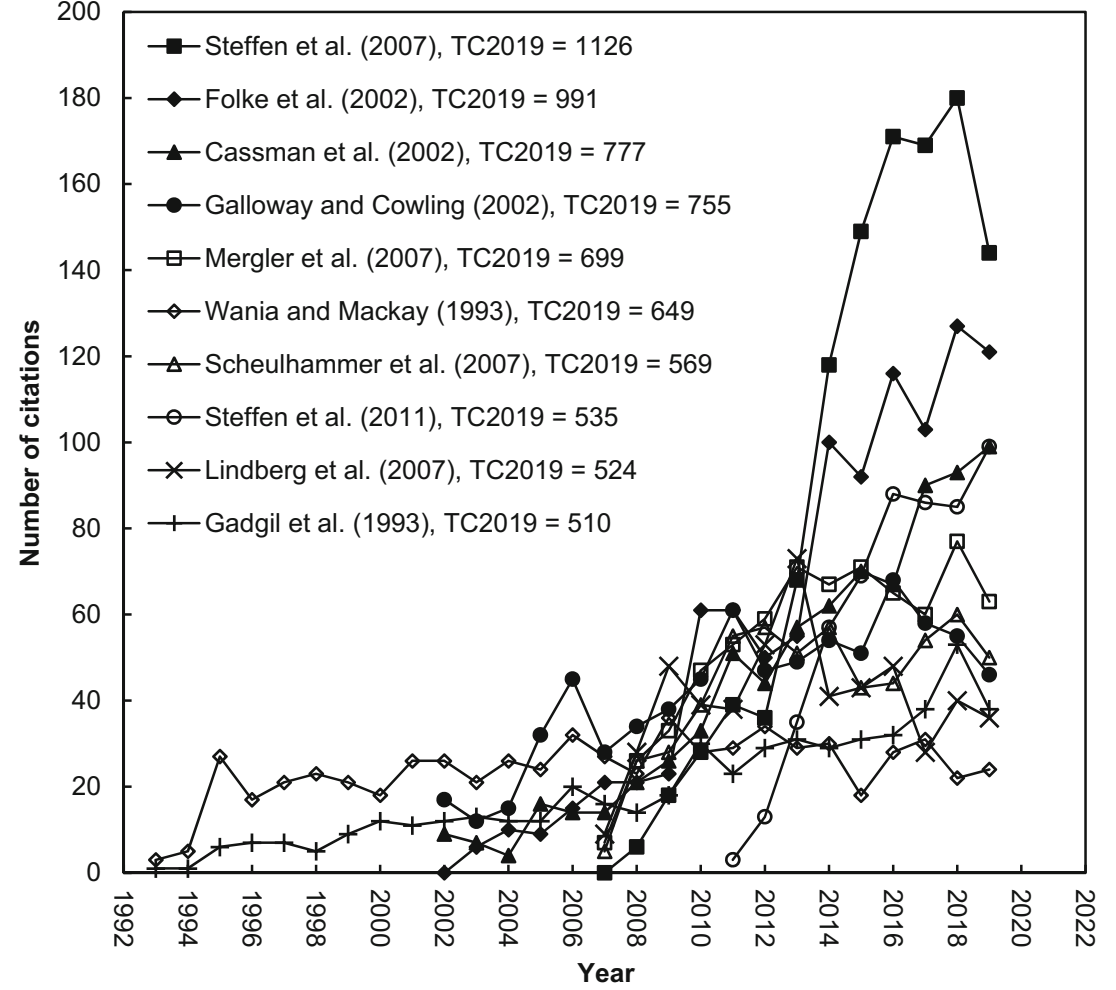

$3.1 \%)$, "governance" (31; 3.1\%), "phosphorus" (26; 2.6\%), "conservation" $(25 ; 2.5 \%)$, and "arctic" $(23 ; 2.3 \%)$. The results of the analysis considered the author's keywords and words in the paper title. Papers having the topics of "Baltic sea" and "climate change" were the most popular in Ambio, with respective scores of 231 and 345 .
Table 7 Top 20 most used words in paper title

\begin{tabular}{lllllll}
\hline Words in title & TP & $80-19 R(\%)$ & $80-89 R(\%)$ & $90-99 R(\%)$ & $00-09 R(\%)$ & $10-19 R(\%)$ \\
\hline Baltic & 218 & $1(6.4)$ & $4(4.3)$ & $4(5.3)$ & $1(7.9)$ & $5(7.4)$ \\
management & 216 & $2(6.3)$ & $13(2.8)$ & $1(6.4)$ & $6(6.4)$ & $3(8.4)$ \\
sea & 204 & $3(6.0)$ & $13(2.8)$ & $8(4.0)$ & $2(7.8)$ & $4(8.3)$ \\
change & 201 & $4(5.9)$ & $269(0.33)$ & $13(3.8)$ & $4(7.1)$ & $1(10)$ \\
environmental & 199 & $5(5.8)$ & $8(3.3)$ & $1(6.4)$ & $5(7.0)$ & $7(6.0)$ \\
climate & 192 & $6(5.6)$ & $80(0.82)$ & $20(2.9)$ & $3(7.7)$ & $2(9.4)$ \\
forest & 166 & $7(4.9)$ & $7(3.5)$ & $3(5.6)$ & $9(5.6)$ & $12(4.4)$ \\
effects & 157 & $8(4.6)$ & $1(5.4)$ & $13(3.8)$ & $8(5.8)$ & $13(4.0)$ \\
water & 156 & $9(4.6)$ & $16(2.6)$ & $17(3.2)$ & $7(6.3)$ & $8(5.7)$ \\
development & 142 & $10(4.2)$ & $1(5.4)$ & $6(4.3)$ & $16(3.7)$ & $20(3.7)$ \\
conservation & 140 & $11(4.1)$ & $6(3.8)$ & $10(3.9)$ & $25(3.1)$ & $9(5.4)$ \\
ecosystem & 133 & $12(3.9)$ & $16(2.6)$ & $41(1.9)$ & $23(3.2)$ & $6(7.1)$ \\
Sweden & 119 & $13(3.5)$ & $12(3.0)$ & $20(2.9)$ & $10(5.3)$ & $32(2.9)$ \\
coastal & 118 & $14(3.5)$ & $19(2.0)$ & $15(3.5)$ & $11(4.8)$ & $28(3.2)$ \\
case & 112 & $15(3.3)$ & $115(0.66)$ & $50(1.7)$ & $12(4.7)$ & $10(5.3)$ \\
biodiversity & 105 & $16(3.1)$ & $\mathrm{N} / \mathrm{A}$ & $5(4.9)$ & $38(2.4)$ & $16(3.8)$ \\
china & 105 & $16(3.1)$ & $47(1.2)$ & $8(4.0)$ & $25(3.1)$ & $25(3.4)$ \\
global & 105 & $16(3.1)$ & $13(2.8)$ & $10(3.9)$ & $27(3.0)$ & $36(2.6)$ \\
marine & 98 & $19(2.9)$ & $11(3.1)$ & $41(1.9)$ & $18(3.6)$ & $29(3.1)$ \\
ecological & 95 & $20(2.8)$ & $32(1.5)$ & $23(2.7)$ & $32(2.6)$ & $16(3.8)$ \\
\hline
\end{tabular}

$T P$, total number of papers; $R$, rank in a decade; $N / A$, not available 


\section{Conclusion}

Research in environmental policy and sustainable development is on the rise. This trend calls for accurate mapping of existing publications in these domains (Gatto et al. 2021; Farrukh et al. 2020). A large number of bibliometrics have been focusing on deducting and examining the essential features and trends for specific journals' research products (Kumar et al. 2020a, b; Arkhipov 1999). Ambio is a top journal in environmental sciences and policy and sustainability studies. Several investigations have conducted bibliometric analyses on journals' publications performances over the years. These facts motivated this paper's rationale in scrutinizing the main publication features of Ambio for the time span 1980-2019. This time frame is the available indexing period for the journal and refer to the Web of Science categories of environmental sciences and environmental engineering - the two original categories for which the journal has been historically indexed.

A total of 3405 papers including 3263 articles and 142 reviews in Ambio from 1980 to 2019 was analyzed. The peak year of citations per publication was found to be the 3rd full year since its publication. The papers published in 2007 and 2002 had a higher impact on the journal. Sweden dominated the performance indicators, ranking first in six publication indicators. Stockholm University and the Swedish University of Agricultural Sciences in Sweden were the best performers. T.V. Callaghan did not only publish the largest number of papers in Ambio but was also the best performer for the categories of first-author paper and corresponding-author papers. The less productive author, J. Rockstrom was, however, the largest journal impact factor contributor.

One-third of the top $100 \mathrm{IF}$ contributing papers were found in the top 100 highly cited papers. Only $45 \%$ of the top 100 most impactful papers in 2019 were listed within the top 100 highly cited papers. Three members of the advisory board in the Ambio-T.V. Callaghan, C. Folke, and T.D. Prowsewere ranked as productive authors. One article published by Rockstrom et al. in 2017 was the top journal impact factor contributing article. An article by Steffen et al. in 2007 was not only the most frequently cited article but also the most impactful publication in 2019. The results show that the journal impact factor contributing papers were not the highly cited papers or the highly impactful publications in Ambio in the most recent available year-2019.

The results in the study provided some initial evidence that highly cited papers in a journal might not necessarily greatly contribute to the journal impact factor. This observation leads to a striking conclusion: it is not always appropriate to use the journal impact factor as an indicator to evaluate the publication performance of institutes and authors. This conclusion may lead to important research, policy, and practical implications in the field of bibliometrics, scientometrics, information science, and publications studies that may be carried on in other papers.

This work also attempted to provide some technical and analytical innovations with respect to the existing scholarship. Some of the novelties proposed in this study are the procedural improvements performed with the scope to render more solid and reliable outputs and avoid overlappings and errors. Additionally, the paper benefited from an enlarged set of new characteristics - that has been investigated along with traditional publication features. These distinct elements allowed for increased precision in the analyses and for broadening the investigation spectrum, returning more accountable results.

Bibliometric analyses can offer a bird's eye perspective on specific timely subjects. This includes specific journals' characteristics and publications trends, as well as quantitative indications on the analyzed literature. However, bibliometrics is unable to yield recommendations on germane publications features, including papers' contents, indications and quality. This is why bibliometrics suggests for integration of qualitative studies on the same bodies of research and mixed methods. In this regard, the paper at hand makes no exception. Future papers may address this issue, disentangling selected characteristics of the examined works. Furthermore, other studies may target different environmental policy and science and sustainability studies journals, as well as further disciplines. Alternative bibliometric techniques, publications databases, papers characteristics, software, and time frames could also be considered. Differentiating the data and the analyses would contribute to better assess the trends and determinants of the sorting sectoral publications.

Availability of data and materials Data will be made available upon request.

Author contribution YSH and AG declare that they have equally contributed.

\section{Declarations}

Ethics approval and consent to participate This material is the authors' own original work, which has not been previously published elsewhere. No humans nor animals were involved in this research. No approval was required.

Consent for publication The paper reflects the authors' own research and analysis in a truthful and complete manner. All authors express their consent to publish.

Competing interests The paper is not currently being considered for publication elsewhere.

Open Access This article is licensed under a Creative Commons Attribution 4.0 International License, which permits use, sharing, adaptation, distribution and reproduction in any medium or format, as long as you give appropriate credit to the original author(s) and the source, 
provide a link to the Creative Commons licence, and indicate if changes were made. The images or other third party material in this article are included in the article's Creative Commons licence, unless indicated otherwise in a credit line to the material. If material is not included in the article's Creative Commons licence and your intended use is not permitted by statutory regulation or exceeds the permitted use, you will need to obtain permission directly from the copyright holder. To view a copy of this licence, visit http://creativecommons.org/licenses/by/4.0/.

\section{References}

Abson DJ, Fischer J, Leventon J, Newig J, Schomerus T, Vilsmaier U, von Wehrden H, Abernethy P, Ives CD, Jager NW, Lang DJ (2017) Leverage points for sustainability transformation. Ambio 46(1):3039. https://doi.org/10.1007/s13280-016-0800-y

Andersson E, Barthel S, Borgström S, Colding J, Elmqvist T, Folke C, Gren $\AA$ (2014) Reconnecting cities to the biosphere: stewardship of green infrastructure and urban ecosystem services. AMBIO 43(4): 445-453

Arkhipov DB (1999) Scientometric analysis of nature, the journal. Scientometrics 46(1):51-72

Baker KH, Kumar S, Pandey N (2021) Five decades of the: a bibliometric analysis. J Consum Aff 55(1):293-331

Baró F, Chaparro L, Gómez-Baggethun E, Langemeyer J, Nowak DJ, Terradas J (2014) Contribution of ecosystem services to air quality and climate change mitigation policies: the case of urban forests in Barcelona, Spain. Ambio 43(4):466-479. https://doi.org/10.1007/ s13280-014-0507-x

Bengtsson J, Angelstam P, Elmqvist T, Emanuelsson U, Folke C, Ihse M, Moberg F, Nystrom M (2003) Reserves, resilience and dynamic landscapes. Ambio 32(6):389-396

Bokhorst S, Pedersen SH, Brucker L, Anisimov O, Bjerke JW, Brown RD, Ehrich D, Essery RLH, Heilig A, Ingvander S, Johansson C, Johansson M, Jonsdottir IS, Inga N, Luojus K, Macelloni G, Mariash H, McLennan D, Rosqvist GN, Sato A, Savela H, Schneebeli M, Sokolov A, Sokratov SA, Terzago S, VikhamarSchuler D, Williamson S, Qiu YB, Callaghan TV (2016) Changing Arctic snow cover: a review of recent developments and assessment of future needs for observations, modelling, and impacts. Ambio 45(5):516-537. https://doi.org/10.1007/s13280-016-0770-0

Callaghan TV, Tweedie CE, Akerman J, Andrews C, Bergstedt J, Butler MG, Christensen TR, Cooley D, Dahlberg U, Danby RK, Daniels FJA, de Molenaar JG, Dick J, Mortensen CE, Ebert-May D, Emanuelsson U, Eriksson H, Hedenas H, Henry GHR, Hik DS, Hobbie JE, Jantze EJ, Jaspers C, Johansson C, Johansson M, Johnson DR, Johnstone JF, Jonasson C, Kennedy C, Kenney AJ, Keuper F, Koh S, Krebs CJ, Lantuit H, Lara MJ, Lin D, Lougheed VL, Madsen J, Matveyeva N, McEwen DC, Myers-Smith IH, Narozhniy YK, Olsson H, Pohjola VA, Price LW, Riget F, Rundqvist S, Sandstrom A, Tamstorf M, Van Bogaert R, Villarreal S, Webber PJ, Zemtsov VA (2011) Multi-decadal changes in tundra environments and ecosystems: synthesis of the international polar year-back to the future project (IPY-BTF). Ambio 40(6): 705-716. https://doi.org/10.1007/s13280-011-0179-8

Cassman KG, Dobermann A, Walters DT (2002) Agroecosystems, nitrogen-use efficiency, and nitrogen management. Ambio 31(2): $132-140$

Chazdon RL, Brancalion PHS, Laestadius L, nett-Curry, A., Buckingham, K., Kumar, C., Moll-Rocek, J., Vieira, I.C.G. and Wilson, S.J. (2016) When is a forest a forest? Forest concepts and definitions in the era of forest and landscape restoration. Ambio 45(5):538-550. https://doi.org/10.1007/s13280-016-0772-y
Chuang KY, Olaiya MU, Ho YS (2012) Bibliometric analysis of the Polish Journal of Environmental Studies (2000-11). Pol J Environ Stud 21(5):1175-1183

Costanza R, Perez-Maqueo O, Martinez ML, Sutton P, Anderson SJ, Mulder K (2008) The value of coastal wetlands for hurricane protection. Ambio 37(4):241-248

Crowley TJ, Lowery TS (2000) How warm was the medieval warm period? Ambio 29(1):51-54

Donthu N, Kumar S, Pandey N, Gupta P (2021) Forty years of the International Journal of Information Management: a bibliometric analysis. Int J Inf Manag 57:102307

Drago C, Aliberti LA (2018) Interlocking directorship networks and gender: a bibliometric analysis. In: IPAZIA workshop on gender issues. Springer, Cham, pp 115-136

Drago C, Agizza V (2019) A bibliometric analysis of the investor shareholder activism. Borders without borders: systemic frameworks and their applications

Farrukh M, Meng F, Raza A, Tahir MS (2020) Twenty-seven years of sustainable development journal: a bibliometric analysis. Sustain Dev 28(6): 1725-1737

Feola G (2015) Societal transformation in response to global environmental change: a review of emerging concepts. Ambio 44(5):376-390. https://doi.org/10.1007/s13280-014-0582-z

Folke C, Carpenter S, Elmqvist T, Gunderson L, Holling CS, Walker B (2002) Resilience and sustainable development: building adaptive capacity in a world of transformations. Ambio 31(5):437-440

Fu HZ, Ho YS (2015) A bibliometric analysis of the Journal of Membrane Science (1976-2010). Electron Libr 33(4):698-713

Gadgil M, Berkes F, Folke C (1993) Indigenous knowledge for biodiversity conservation. Ambio 22(2-3):151-156

Gaeta TJ (1999) Authorship: "law" and order. Acad Emerg Med 6(4): 297-301

Galloway JN, Cowling EB (2002) Reactive nitrogen and the world: 200 years of change. Ambio 31(2):64-71

Garfield E (1997) Dispelling a few common myths about journal citation impacts. Scientist 11(3):11

Garfield E (1999) Journal impact factor: a brief review. Can Med Assoc J 161(8):979-980

Gatto A (2020) A pluralistic approach to economic and business sustainability: a critical meta-synthesis of foundations, metrics, and evidence of human and local development. Corp Soc Responsib Environ Manag 27(4):1525-1539

Gatto A, Drago C (2020) A taxonomy of energy resilience. Energy Policy 136:111007. https://assets.researchsquare.com/files/rs-103974/v1/ 34e4da5b-5aa6-4bb2-9d58-817741c309e7.pdf

Gatto A, Drago C, Ruggeri M (2020) On the frontline - sustainability and development research amidst the COVID-19 pandemic. https:// assets.researchsquare.com/files/rs-103974/v1/34e4da5b-5aa64bb2-9d58-817741c309e7.pdf

Gatto A, Drago C (2021) When renewable energy, empowerment, and entrepreneurship connect: measuring energy policy effectiveness in 230 countries. Energy Res Soc Sci 78:101977

Gatto A, Loewenstein W, Sadik-Zada ER (2021) An extensive data set on energy, economy, environmental pollution and institutional quality in the petroleum-reliant developing and transition economies. Data in Brief 35:106766

Graneli E, Wallstrom K, Larsson U, Graneli W, Elmgren R (1990) Nutrient limitation of primary production in the Baltic Sea area. Ambio 19(3):142-151

Haase D, Frantzeskaki N, Elmqvist T (2014) Ecosystem services in urban landscapes: practical applications and governance implications. Ambio 43(4):407-412. https://doi.org/10.1007/s13280-014-0503-1

Ho YS (2018) Comments on "Mapping the scientific research on nonpoint source pollution: a bibliometric analysis" by Yang et al. (2017). Environ Sci Pollut Res 25(30):30737-30738. https://doi. org/10.1007/s11356-017-0381-8 
Ho YS (2019) Bibliometric analysis of the Journal of Orthopaedic Research from 1991 to 2018. Orthopedic Res Online J 6(2):574 584. https://doi.org/10.31031/OPROJ.2019.06.000632

Ho YS, Gatto A (2020) A bibliometric analysis of COVID-19 research. https://www.preprints.org/manuscript/202012.0624/v1

Ji L, Liu CW, Huang LC, Huang GH (2018) The evolution of resources conservation and recycling over the past 30 years: a bibliometric overview. Resour Conserv Recycl 134:34-43. https://doi.org/10. 1016/j.resconrec.2018.03.005

Kumar S, Madhavan V, Sureka R (2020a) The journal of emerging market finance: a bibliometric overview (2002-2019). J Emerg Mark Finance 19(3):326-352

Kumar S, Marrone M, Liu Q, Pandey N (2020b) Twenty years of the international journal of accounting information systems: a bibliometric analysis. Int J Account Inf Syst 39:100488

Larsson U, Elmgren R, Wulff F (1985) Eutrophication and the Baltic Sea: causes and consequences. Ambio 14(1):9-14

Lindberg S, Bullock R, Ebinghaus R, Engstrom D, Feng XB, Fitzgerald W, Pirrone N, Prestbo E, Seigneur C (2007) A synthesis of progress and uncertainties in attributing the sources of mercury in deposition. Ambio 36(1):19-32. https://doi.org/10.1579/0044-7447(2007) 36[19:ASOPAU]2.0.CO;2

Liu JG, Dietz T, Carpenter SR, Folke C, Alberti M, Redman CL, Schneider SH, Ostrom E, Pell AN, Lubchenco J, Taylor WW, Ouyang ZY, Deadman P, Kratz T, Provencher W (2007) Coupled human and natural systems. Ambio 36(8):639-649. https://doi.org/ 10.1579/0044-7447(2007)36[639:CHANS]2.0.CO;2

Madronich S, Mckenzie RL, Caldwell M, Bjorn LO (1995) Changes in ultraviolet radiation reaching the earth's surface. Ambio 24(3):143-152

Matson P, Lohse KA, Hall SJ (2002) The globalization of nitrogen deposition: consequences for terrestrial ecosystems. Ambio 31(2): 113-119

Mattsson P, Sundberg CJ, Laget P (2011) Is correspondence reflected in the author position? A bibliometric study of the relation between corresponding-author and byline position. Scientometrics 87(1):99-105

Mergler D, Anderson HA, Chan LHM, Mahaffey KR, Murray M, Sakamoto M, Stern AH (2007) Methylmercury exposure and health effects in humans: a worldwide concern. Ambio 36(1):3-11. https:// doi.org/10.1579/0044-7447(2007)36[3:MEAHEI]2.0.CO;2

Monge-Nájera J, Ho YS (2016) Bibliometry of the Revista de Biología Tropical/International Journal of Tropical Biology and Conservation: document types, languages, countries, institutions, citations and article lifespan. Rev Biol Trop 64(3):1223-1235

Munthe J, Bodaly RA, Branfireun BA, Driscoll CT, Gilmour CC, Harris R, Horvat M, Lucotte M, Malm O (2007) Recovery of mercurycontaminated fisheries. Ambio 36(1):33-44. https://doi.org/10. 1579/0044-7447(2007)36[33:ROMF]2.0.CO;2

Nihlgard B (1985) The ammonium hypothesis: an additional explanation to the forest dieback in Europe. Ambio 14(1):2-8

Obrist D, Kirk JL, Zhang L, Sunderland EM, Jiskra M, Selin NE (2018) A review of global environmental mercury processes in response to human and natural perturbations: changes of emissions, climate, and land use. Ambio 47(2):116-140. https://doi.org/10.1007/s13280017-1004-9

Pierpaoli M, Ruello ML (2018) Indoor Air Quality: a bibliometric study. Sustainability. 10(11) Article Number: 3830. https://doi.org/10. $3390 /$ su10113830

Rabalais NN (2002) Nitrogen in aquatic ecosystems. Ambio 31(2):102-112

Rockstrom J, Williams J, Daily G, Noble A, Matthews N, Gordon L, Wetterstrand H, DeClerck F, Shah M, Steduto P, de Fraiture C, Hatibu N, Unver O, Bird J, Sibanda L, Smith J (2017) Sustainable intensification of agriculture for human prosperity and global sustainability. Ambio 46(1):4-17. https://doi.org/10.1007/s13280-0160793-6
Scheulhammer AM, Meyer MW, Sandheinrich MB, Murray MW (2007) Effects of environmental methylmercury on the health of wild birds, mammals, and fish. Ambio 36(1):12-18. https://doi.org/10.1579/ 0044-7447(2007)36[12:EOEMOT]2.0.CO;2

Schoumans OF, Bouraoui F, Kabbe C, Oenema O, van Dijk KC (2015) Phosphorus management in Europe in a changing world. Ambio 44(S2):S180-S192. https://doi.org/10.1007/s13280-014-0613-9

Sharpley AN, Bergstrom L, Aronsson H, Bechmann M, Bolster CH, Borling K, Djodjic F, Jarvie HP, Schoumans OF, Stamm C, Tonderski KS, Ulen B, Uusitalo R, Withers PJA (2015) Future agriculture with minimized phosphorus losses to waters: research needs and direction. Ambio 44(S2):S163-S179. https://doi.org/10.1007/s13280-014-0612-x

Smith DR (2009) A 30-year citation analysis of bibliometric trends at the Archives of Environmental Health, 1975-2004. Arch Environ Occup Health 64(S1):43-54. https://doi.org/10.1080/19338240903293004

Smith DR, Leggat PA (2009) Estimation of some missing bibliometric indicators at Industrial Health. Ind Health 47(2):202-203. https:// doi.org/10.2486/indhealth.47.202

Söderström B (2014) Changes in AMBIO policies. Ambio 43(5):557558. https://doi.org/10.1007/s13280-014-0542-7

Steffen W, Crutzen PJ, McNeill JR (2007) The Anthropocene: are humans now overwhelming the great forces of nature. Ambio 36(8):614-621

Steffen W, Persson A, Deutsch L, Zalasiewicz J, Williams M, Richardson K, Crumley C, Crutzen P, Folke C, Gordon L, Molina M, Ramanathan V, Rockstrom J, Scheffer M, Schellnhuber HJ, Svedin U (2011) The anthropocene: from global change to planetary stewardship. Ambio 40(7):739-761. https://doi.org/10.1007/s13280-011-0185-x

Tengo M, Brondizio ES, Elmqvist T, Malmer P, Spierenburg M (2014) Connecting diverse knowledge systems for enhanced ecosystem governance: the multiple evidence base approach. Ambio 43(5): 579-591. https://doi.org/10.1007/s13280-014-0501-3

Vega-Arce M, Salas G, Núñez-Ulloa G, Pinto-Cortez C, Fernandez IT, Ho YS (2019) Research performance and trends in child sexual abuse research: a Science Citation Index Expanded-based analysis. Scientometrics 121(3):1505-1525. https://doi.org/10.1007/s11192019-03267-w

Verheyen K, Vanhellemont M, Auge H, Baeten L, Baraloto C, Barsoum N, Bilodeau-Gauthier S, Bruelheide H, Castagneyrol B, Godbold D, Haase J, Hector A, Jactel H, Koricheva J, Loreau M, Mereu S, Messier C, Muys B, Nolet P, Paquette A, Parker J, Perring M, Ponette Q, Potvin C, Reich P, Smith A, Weih M, SchererLorenzen M (2016) Contributions of a global network of tree diversity experiments to sustainable forest plantations. Ambio 45(1):29 41. https://doi.org/10.1007/s13280-015-0685-1

Wang MH, Yu TC, Ho YS (2010) A bibliometric analysis of the performance of Water Research. Scientometrics 84(3):813-820. https:// doi.org/10.1007/s11192-009-0112-0

Wania F, Mackay D (1993) Global fractionation and cold condensation of low volatility organochlorine compounds in polar regions. Ambio 22(1):10-18

Wilkinson C, Linden O, Cesar H, Hodgson G, Rubens J, Strong AE (1999) Ecological and socioeconomic impacts of 1998 coral mortality in the Indian Ocean: an ENSO impact and a warning of future change? Ambio 28(2):188-196

Xu ZS, Zhou W, Baltrènaite E (2019) Comprehensive bibliometric study of Journal of Environmental Engineering and Landscape Management from 2007 to 2019. J Environ Eng Landsc Manag 27(4):215-227. https://doi.org/10.3846/jeelm.2019.11366

Publisher's note Springer Nature remains neutral with regard to jurisdictional claims in published maps and institutional affiliations. 